\title{
Nascent Leadership Behaviors
}

Dennis L. Payette, Adelphi University, USA

Anthony F. Libertella, Adelphi University, USA

\begin{abstract}
This paper is a compendium of leadership behaviors that emerging or aspirant leaders could choose to enhance their management and leadership skills. These behaviors were drawn directly from the experience of the authors, both of whom have held senior leadership and management positions in business, law, and higher education. This paper is an outgrowth of more than a decade of experience in teaching leadership in graduate MBA programs and in undergraduate business policy and strategy capstone courses. MBA programs typically have a dedicated course on leadership and undergraduate capstone courses focus on leadership, business policy and strategy. Normally course material is presented through case studies, readings and lectures on leadership and leadership theory. Most, although not all, students have limited or no management experience and they hope to advance their management and leadership skills which they believe should in turn result in their career success. During our years of teaching leadership, many students asked the authors about specific leadership actions they could utilize in their nascent business careers. The material presented in this paper is oriented towards practical and actionable steps that the aspiring leader can decide to apply with the caveat that common sense and sensitivity to the individual circumstances will vary greatly. However, sooner or later the right time to distinguish oneself will surely occur and that the behaviors presented in this paper can be of value to entry and junior level managers.
\end{abstract}

Keywords: ambition; corporate culture; crisis management; empathic leader; leadership; malingerers; management by walking around; nascent leadership; passion

\section{INTRODUCTION}

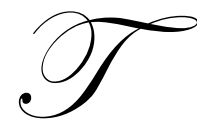

his article offers behavioral insight and advice for emerging leaders in their quest to enhance their career and leadership potential. The article consists of six general categories of behaviors and describes within these categories certain practices that can lead to leadership success. The behaviors will act as a reality check for nascent leaders so they can adopt those behaviors most beneficial to their own unique business setting.

Drawing from decades of conversations with senior executives we were informed that a business education has provided students with the empirical, quantitative and analytical skills needed to function at their job. Nevertheless, these same executives further emphasized that frequently nascent leaders lacked the practical "real world" behaviors needed to enhance their job performance as well as upgrade their leadership potential. Conversely, these executive sentiments have been confirmed by commentary provided to us by our former undergraduate and graduate students. Through informal group discussions and individual interviews, students informed us that their core courses and specialized courses in business provided them with a sound academic understanding of business, but failed somewhat to provide them with the practical orientation of the "real world" behaviors that they could apply immediately towards their leadership journey.

Today, retaining a decent job seems to be a constant challenge for the nascent leader. Our experience of having held senior leadership positions and a decade of experience in teaching leadership have encouraged us to provide insights that we have learned that might enhance nascent leaders to attain job promotions which in turn will enable them to climb the leadership ladder. We have simply tried to share some practical advice that evolved from our observations to discern those behaviors that made certain individuals emerge as successful leaders. 
The article is not intended for senior level executives near the top rung of leadership power. Instead, the article is intended for the nascent leader whose leadership path has just begun or for middle management leaders. In other words, we believe that certain business behaviors if judiciously practiced will enable the nascent leader to have a long and rewarding career where their leadership potential can flourish. Individuals who achieved leadership success tends to possess early on in their careers certain work behaviors. Their "modus operandi" for leadership success was accomplished by an orientation grounded in simple practical behaviors. Most significant, the nascent leader can acquire these behaviors to enhance their leadership potential. The behaviors discussed are not the final word in order for the nascent leader to advance in the workplace. The literature is replete with suggestions on how leaders can and should succeed. The bibliography attached to this article is a compendium of books that deal with all types of leaders which serves as valuable resources for this subject. Nevertheless, our focus for the article is exclusively on addressing the nascent leader with little or no management experience. The behaviors chosen and discussed emanate from our business and academic experiences with the belief that if nascent leaders mindfully adopt and diligently practice these behaviors, success may follow.

The article is organized along simple lines. We will introduce six general behavioral categories. Each category contains several specific behaviors which initially will be identified. Next, each identified behavior will be described in some detail in order to understand its meaning. Thereafter, an application of each behavior will be presented to provide practical guidelines to be followed by the nascent leader. Finally, a concluding discussion is presented on the challenges that confront the nascent leader with special emphasis on a call for action.

\section{CATEGORY I - MAKE YOURSELF INDISPENSABLE}

\section{Behavior: 1}

Get Your Career Moving!

\section{Description:}

Why do some people get noticed more than others as potential leadership material in organizations? What can you do to get out of the pile and get on a leadership track? Like so many things in life and business it never seems to be one or two activities but rather a series of steps, decisions, moves, and deliberate actions that one takes to bypass the competition.

\section{Application:}

First, you must observe successful leaders, managers and supervisors and note how they have enhanced their careers. What specific things have they done to be promoted (or in some cases not done). Next, do not hesitate to ask role models/mentors what significant actions and behaviors led to their promotions and career development. Finally, scan internal company communications and newsletters for clues as to what are your organization's values and rewards.

\section{Behavior: 2 \\ Work hard to be noticed!}

\section{Description:}

Successful leaders consistently indicate that throughout their work experience, it was a simple fact of life that they never had to work less but more - not just for time spent but for results delivered.

\footnotetext{
Application:

Diligence in all that you do will pay off sometimes quickly and sometimes when you least expect it. Just be ready to take on new challenges or opportunities your supervisor makes available to you. Surprisingly, many individuals do not jump at difficult tasks as there may be risks involved. However, the benefits may be very significant and worth taking a few chances. One can learn a great deal from failure. Many accomplished leaders often point to failures as one of their best sources of learning.
} 
Behavior: 3

Think about your decisions!

\section{Description:}

Making good decisions proves to be significant. Ask Peter Drucker - if you don't know who he is, find out-he said making good decisions is the essence of management. Indecision is deadly. The leader's ability to confront problems and make thoughtful decisions is vital.

\section{Application:}

Successful decision makers follow a thought process that considers the options, evaluates the risks and benefits, and finally decides. IBM was built on a simple organizational motto, "Think". Most important, demonstrate your ability to make decisions under stress or in a crisis. Your crisis decision thought process is to figure out the best course of action as it applies to your circumstances and proceed in a calm and deliberate manner. Thereafter, step forward with your plans or ideas and be prepared to implement what you suggest. Supervisors are looking for solutions in problem situations. They will frequently ask the proponents of solutions to implement them. For a nascent leader, gaining the reputation as a problem solver will catapult you on the fast track to promotion, recognition, and reward.

\section{Behavior: 4}

Demonstrate broad based knowledge!

\section{Description:}

As a knowledge worker, stay alert, think out of the box, and keep informed of important developments in your field and related fields.

\section{Application:}

You should read, listen, study and connect with people who have specialized knowledge that you can draw upon. Convert that knowledge into suggestions or plans to enhance your leadership skills and knowledge base.

\section{Behavior: 5}

Ambition is good!

\section{Description:}

Unbridled ambition will eventually get you off the fast track. Therefore, exhibit keen interest in advancement by your performance not just by the expression of ambition.

\section{Application:}

Demonstrate proper ambition by your daily performance, your quality of work and when appropriate (sometimes a difficult choice) in discussion with your supervisor. During performance evaluation processes ask for specific things that you can do to improve and_advance toward promotion.

\section{Behavior: 6 \\ Going to work!}

\section{Description:}

Individuals known for their reliability is an essential characteristic of those considered for promotion and career advancement. This includes going to work on off days when necessary, staying late to finish projects, coming in early to get a head start on important business and presentations. Yes, this can be carried to extremes and that is not recommended as excessive zeal can lead to burnout (mental and physical) and diminished quality of work performance. Some Asian work cultures, Japan, for example, extol extreme work commitment as a cultural concept that is difficult to breach. Nonetheless, with good judgment and alertness to this important behavior, leaders do work hard and if you cannot or will not, you may lose out in the competition for advancement. 


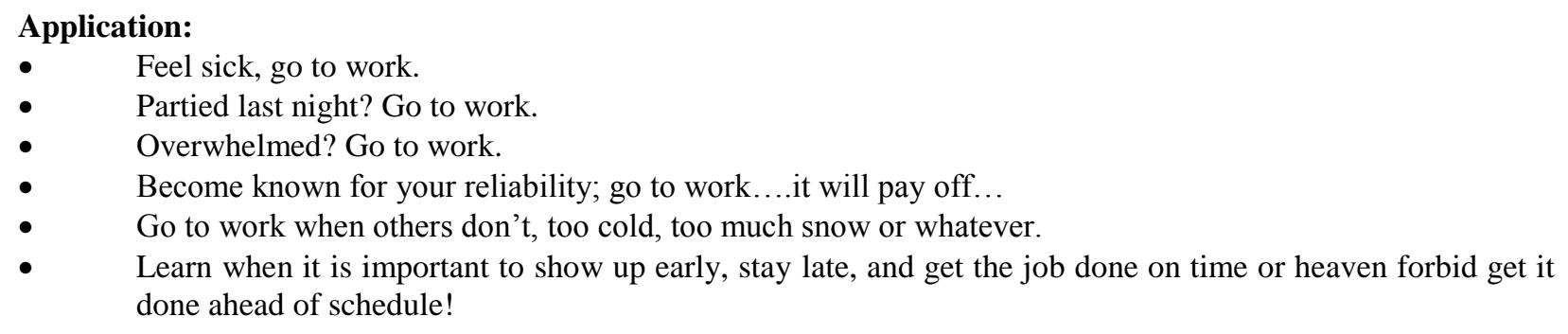

\section{Behavior: 7}

Specialized talents!

\section{Description:}

Become known for that extra dimension you bring to the table such as being reliable under stress, that is, being able and willing to do what others cannot or will not do (within your ethical limits). Authority comes from expertise that others do not have. It is a given that all jobs have their particular requirements and duties that everyone else in similar lines must likewise have. Acquiring skills, knowledge and special talents beyond the normal requirements of one's position highlights your value to your department or to the organization as a whole. Staying alert to new challenges, understanding what your company does, such as the heightened awareness of environmental and sustainability mandates, represent an opportunity for you to gain specialized skills appropriate to these or other future trends to be addressed. The pace of change is relentless so being in the forefront of new trends will depend on how alert you are to the challenges that others may not perceive as important.

\section{Application:}

You must gain specialized skills within technical and/or behavioral realms, such as, learning the latest developments in computer based hardware and software that you can use when others may not care to or are not required to learn. To set you apart from individuals who are content with the status quo, you must constantly enhance your communication skills, and if possible, attain an extra certification or even an additional degree in a technical or behavior specialization.

\section{Behavior: 8}

Know your theories!

\section{Description:}

Mention theories at work and eyes roll, quizzical expressions appear and tuning out follows. Paradoxically, leaders know their theories, that is, they are generally aware of key ideas and concepts derived from theories such as McGregor's classic Theory X and Y, Ouichi's theory Z, Maslow's hierarchy of needs, and Hetzberg's work on motivation. Each of these theories and others helps one to understand and therefore predict behavior of an adversary or competitor. This theory based knowledge can be an enormous and entirely ethical advantage for a leader to possess. With passage of time, new theories emerge to explain behavior and phenomena. Therefore, it behooves you, the nascent leader, to stay abreast of key ideas in leadership and management. One such example, as demonstrated in this article, is the concept of empathic management, i.e., coming to know what your employees think and feel with respect to what it takes to achieve management goals.

\section{Application:}

Simply put, knowing your management theories can give you greater ability to predict how people may act in different circumstances. This ability when wisely applied can lead you to make better decisions which, according to one of the wisest management sages, Peter Ducker, are the essence of management. 
Behavior: 9

Know your facts!

\title{
Description:
}

For a nascent leader nothing could be more harmful than having ones facts wrong in a staff meeting or with clients. Conversely, being known for accuracy, thoroughness and sound judgment (often under stressful circumstances) is a major leadership behavior that counts more than you may know. Few leaders achieve much success without very thorough preparation and the well honed competencies to confidently make decisions.

\section{Application:}

Check your facts, double check your facts and embrace learning new things continuously. Note the egregious failures of those who relied on unsubstantiated data. In a defensive sense, look for flaws that could harm your company and make suggestions on how to fix them. Your supervisors and your peers will be grateful.

\section{Behavior: 10 \\ Leadership is a choice!}

\section{Description:}

Leadership is an extraordinarily complex process which is both an art and a science. Leadership will be your choice based upon the adoption of crucial behaviors. Rarely will leadership find you, you must find it.

\begin{abstract}
Application:
Leadership is an outcome process, that is, leadership develops and happens to a person only after making decisions, developing skills, attitudes, and many choices along the way. Good leaders understand the mechanics (processes) and the art (behaviors) correlated with achieving positions of leadership. What some may regard as luck in becoming a leader is rarely the cause and bad luck is rarely the reason for not becoming a leader. Leadership literature is replete with theories, studies, cases, and examples of what works and what does not. It must begin with a conscious choice on your part to become a leader not wait for it to simply happen.
\end{abstract}

\section{CATEGORY II - BUILDING RELATIONSHIPS INSIDE AND OUTSIDE}

\author{
Behavior: 11 \\ Build your networking file relentlessly!
}

\section{Description:}

You should ask for business cards, email addresses, phone numbers when appropriate and do not be bashful about it. Most surprisingly, when you least expect it someone you met somewhere turns out to be just the person you need to contact or has information you need. If you misplace or fail to save contact information you may have missed an opportunity to shine. Wonderful new technologies exist that makes keeping track of contacts much simpler than ever. Love your Blackberry, Iphone, and Ipad.

\section{Application:}

When you attend conferences, meetings, and other work related events, scope out who you would like to meet. Most people feel awkward about simply approaching someone they don't know. Just do it. Be polite of course and apologize but take that chance and simply introduce yourself and say something flattering about that person. You will know right away if the "target" is receptive to you or not. If yes, chat away and be sure to offer your business card and ask for theirs. You should be careful not to over stay the conversation and politely withdraw by thanking the person for their time and tell them to contact you if there is any way you might be of assistance to them. This approach will not work every time but it will succeed more often than not. 
Behavior: 12

Attend company functions!

\section{Description:}

Be seen and socialize. Network, network, network....anytime you can, just make sure you are not obnoxious or pushy. Leaders are rarely shy and new leaders must acquire and hone their social skills.

\section{Application:}

Attendance at social and/or business related meetings should be viewed as an opportunity to gather ideas that you can use in your work. If you come away from a meeting or conference with just one or two ideas that you can actually use, the time will be well spent. Next, look at social and conference events, not as obligations, but as opportunities to harvest ideas, contacts, and who knows even job opportunities. Be particularly careful at company social functions to avoid being influenced by alcohol (or any other mind or mood altering substance). Careers can be enhanced by honing your social skills and careers can be destroyed by inappropriate revelry.

\section{Behavior: 13}

Surround yourself with the best people!

\section{Description:}

Making good personnel decisions is hard work. Most managers have failed miserably on more than one occasion. Force yourself to work harder at making the right choices for staff openings. Next, if you surround yourself with really good people you will stand out by achieving good results.

\section{Application:}

An egregious error that insecure and inexperienced managers frequently make is to hire non threatening personnel, otherwise known as minions. Servile staff may make you feel good but it is a sure path to mediocrity. Minions will destroy your efforts sooner or later. Assume every person on your staff is potentially an extremely valuable asset to you, to your business unit, and to the company as a whole. Therefore, look at the hiring process as one of your most important functions. Personnel are your most expensive assets. They are difficult to find, often hard to keep and very costly and time consuming to replace. Successful leaders look to surround themselves with people at least as good as they are.

You want people who will be secure enough to challenge your ideas because they know you will listen; if not always agree with you.

\section{Behavior: 14}

Build great teams!

\section{Description:}

The previous leader behavior focused on surrounding oneself with high quality personnel. The emphasis in this behavior is to stack your project teams with these highly qualified people.

\section{Application:}

Your job is to create great teams. Give teams clear objectives and task goals; provide the resources they need to accomplish the task; provide encouragement and support along the way; make adjustments when needed; and finally, celebrate the results. Good leaders know how to motivate great teams as it is one of the leaders' most rewarding functions. In essence, build great teams, support them well, and reap the benefits.

\section{Behavior: 15}

Stay informed about your business! 


\section{Description:}

Stay informed means reading more than you might like but do it anyway. Successful leaders are constantly availing themselves of top sources of information such as, the Economist, Fortune, Wall Street, the New York Times and Bloomberg News. Most information can be accessed on the web and web subscriptions are expanding rapidly. Use your Iphone or Ipad and read top business books on your EReader or kindle when traveling. Libraries are now providing loaner EBooks at minimal rates.

\section{Application:}

Leaders find the time to stay informed, some by allocating a regular time slot, some by reading at night or early morning, and while traveling. Be the first to know about new developments and critical information that may impact upon your business. Your personal network of business friends is another important source of information. In addition, you should call for periodic staff meetings and discuss new developments that pertain to your industry.

\section{Behavior: 16 \\ Join community groups!}

\section{Description:}

Join community groups that are related to your company or job. Some companies actually require this of their managers.

\section{Application:}

There are many advantages for leaders to join community groups. Most likely the community and your company will have mutual interests in maintaining open channels of communication. This open communication process will limit or prevent unfortunate situations from developing based on misinformation. You should become a member of local service clubs such as, the Lions or Rotary Club, as a good way to meet community activists and to learn about what important issues are within the community. As an aspiring leader, it is good to be seen as an involved member of the community as opposed to being an antagonist. Good friendships often develop from participation and sponsorship of golf outings and similar community events.

\section{Behavior: 17}

Know your corporate culture!

\section{Description:}

Not knowing the corporate culture may well work against you. Corporate culture represents the traditions, the rules, the codes, both formal and informal, sometimes written and sometimes not, of your particular organization. These standards and codes often emanate from founders' ideas and standards. Therefore, you must make the culture work on your behalf.

\section{Application:}

McGraw-Hill Corp. is quite explicit about their culture and company regulation. They require every new employee to read a booklet that details expectations concerning ethics, work performance and generally all standards that are expected to be complied with. Some companies are not as precise as McGraw-Hill Corp.; therefore, it is wise for nascent leaders to make every effort to learn about what is expected of them. One must be proactive on this matter in order to prevent embarrassment or worse.

\section{Behavior: 18}

Entertain at home!

\section{Description:}

Entertaining at home can be an excellent way to develop good business relationships. Entertaining at home does not have to be a major production but a dinner party of six to eight is appropriate and an informal way to build good relationships. 


\section{Application:}

You must know how to socialize and entertain as a mean of both reward, celebration, or simply to create greater familiarity among invited guests. Socializing with clients, staff members, and community leaders engenders goodwill, friendships and loyalty.

\section{Behavior: 19}

Praise is free!

\section{Description:}

Use praise freely for those who have earned it! How easy it is in the freneticism of our work that we can forget to give that simple "thank you" to anyone who has done something well. Yet, a bit of praise, liberally sprinkled about can improve morale immensely.

\section{Application:}

Good leaders know the value of praise and find ways to use it effectively. Jack Welsh was famous at GE for his handwritten notes of thanks to those he ran across while touring GE facilities around the world. Loyalty and respect are earned by leaders who do not forget those that helped them along the way. Of course, there are many ways to say thanks. Mary Kay of the cosmetics empire strongly believed in saying thanks to every top performer at her company's annual celebrations. She gave away cars, trips and other prizes to successful sales reps from all over the world. You should use praise judiciously i.e. saying thanks to a deserving employee by giving a few days of extra vacation time can mean a great deal. Conversely, if you praise your supervisor disingenuously, this may or may not inure to your benefit.

\section{Behavior: 20}

The empathic leadership approach!

\section{Description:}

An emerging theory in management is called "Empathic Leadership." Empathy is the vicarious ability of one person to sense what another person is experiencing and feeling. Empathic management is the application of this concept. It suggests that managers and leaders use an empathic approach to create working conditions that relate to what the employee is experiencing in order to perform their duties better. Further, the empathic concept may lead to better leadership through decisions that are meaningful to the employee and eliminate impediments to better job performance.

\section{Application:}

Leaders who are aware of the empathic model and take initiatives to enhance the task environment for employees will experience a higher regard from employees for being more sensitive to their actual work demands. As an empathic leader you will become more adept at avoiding decisions that may be counter productive to employee performance and morale. The empathic model requires you to apply behaviors such as caring, listening and respect to the organizational construct.

\section{CATEGORY III - COMMUNICATION MATTERS}

\section{Behavior: 21 \\ Volunteer to speak!}

\section{Description:}

Leadership almost always goes hand in hand with good communication skills. Communication is an acquired skill and the more you do it the better you get. Volunteer to speak or make presentations in-house, at conferences or to clients. 


\section{Application:}

It is worth noting that for some people nothing frightens and inhibits them more than public speaking. Likewise, few behaviors can benefit your career more than building your communications skills, particularly oral presentation skills. Can you think of any leader that does not possess such skills? While there are a few they are by far the exception to the rule. Look for opportunities to speak within the company, outside the company and at community or professional meetings. Volunteer to do presentations in conferences and share the information with colleagues when you get back. Be suspicious of those who claim that such presentations are irrelevant.

\section{Behavior: 22}

Write for recognition!

\section{Description:}

Getting your name in "print" whether in electronic, traditional or even audio format for newsletter, journals, or professional publicists will enhance your status and reputation. Never assume you have nothing to say!

\section{Application:}

Writing like public speaking is not easy, yet it is a skill that with practice that can and will get better. The challenge of writing is often forcing oneself to sit down and write. Due to word processing technologies, writing is much easier than years past. Volunteer to do meeting minutes, write proposals, write for your own work teams, and look for opportunities to write in your community newspaper. A whole new era of writing has also emerged in social networking, blogging and the like.

\section{Behavior: 23}

What language do you know?

\section{Description:}

Some people have foreign language skills that they overlook as not being useful. This assumption can be a mistake in light of the fact that major corporations are extending their market reach throughout the world. Consequently, the nascent leader with foreign language capabilities will surely prove to be a valuable resource for their organization.

\section{Application:}

Globalization of business and communication technologies makes having any foreign language skill an asset for you and your company. Be sure your company records and current resume reflect your language prowess. However, be honest about your skill level, i.e. ranging from conversational to writing and reading skills.

\section{Behavior: 24}

Management by Walking Around - M.B.W.A!

\section{Description:}

As the title implies, a great deal can be learned from this behavior - i.e., simply finding time to walk around your store, your plant, your institution, your departments, your divisions, your clients, your customers and your employees.

\section{Application:}

Most successful leaders constantly roam through the working corridors to gain better insight about their organization by listening to their employees and their customers. For example, employees relish the opportunity to be heard by leaders which in turn may prove to be beneficial to leaders by learning about important ideas, suggestions or problems as they walk around. 


\title{
CATEGORY IV- GET IT DONE AND DELIVER RESULTS
}

\author{
Behavior: 25 \\ "I want to do more" works amazingly well!
}

\section{Description:}

If you think you are capable of doing more in your current job think about simply telling your boss that you would like to be considered for a special assignment, additional duties, or opportunities to demonstrate some skills you think may be unrecognized.

\section{Application:}

Volunteering for extra duty or special assignments is not something many people decide to do. The volunteering initiative is an advantage for you since supervisors are happy, if not thrilled, when someone does come forward without being asked to do more. It stands to reason that when promotions are available, those who have "gone the extra mile" will be among the first to be considered.

\section{Behavior: 26}

Thinking and acting strategically!

\section{Description:}

Thinking strategically means assessing the internal and external task environments to determine a course of action for your job, your department, and or the organization as a whole. Leaders analyze the crucial challenges confronting their organization, choose strategies, and execute the strategic initiatives to move the company forward. Many good strategic plans have withered when not properly executed.

\section{Application:}

Strategic resilience, nimbleness, ability to adjust, adaptability and flexibility are all qualities essential for the nascent leader. If you can execute the strategic activities that really matter and most of all get them done well- promotions will follow.

\section{Behavior: 27}

Work smarter, and smarter!

\section{Description:}

So often the difference between one who advances is not how hard a person works but how smart they work. Stick to priorities and avoid doing that which is not essential.

\section{Application:}

Working smarter may involve taking a course, a special seminar, learning new software to meet special circumstances (at your own expense if necessary), to find those best practices or methods recently proven to be successful. Acquiring technical expertise that others do not have can give one a distinct advantage which is likely to be observed and rewarded. Simply writing lists of key tasks to be done and sticking to those priorities on a daily basis will improve your productivity and effectiveness.

\section{Behavior: 28}

Find time to think!

\section{Description:}

Thinking is an acquired skill too often over looked. In the hustle and bustle of work demands we often say, "I have no time even to think!" Not only is that untrue but it is restricting your work performance. Time management training says that we have the time but, the issue is how we choose to use the time we have. Decisions have to be 
made to carve out time from how we habitually waste our time. Reallocate time for contemplative thinking on things that matter to you, your family and your work.

\section{Application:}

Jot down ideas; record them somewhere so you can return to them. Successful thinkers find ways to focus on ideas. Executives block out time in their schedules, some think while exercising, praying, meditating, and taking a walk. Good leaders always find time to think - so can you.

\section{Behavior: 29}

Crisis management!

\section{Description:}

Look at crises as opportunities not impediments.

\section{Application:}

Most individuals shy away from crises. Therefore, it is unnatural to suggest that one actually embrace crises. Demonstrating your willingness to tackle the tough task under less than optimal circumstances is an excellent leadership behavior. Your calm and reasoned approach may make a significant difference in the actions and decisions made during a crisis. Your ability to confront a crisis with resolve and resilience will not go unnoticed.

\section{Behavior: 30}

The four options at work!

\section{Description:}

- Do everything you can to effect changes you think necessary

- Get content with your circumstances

- Resign if it is the right thing to do

- Staying and whining or constantly complaining is not an available option.

\section{Application:}

Actually, there are only three legitimate options at work; the fourth is simply a negative behavior that usually imperils your job. It is options one and two that you will most likely engage during your work experiences. When these efforts are no longer possible, then you should consider option number three, which is to resign. The economy dictates against hasty resignations. However, if you no longer feel able to improve or change work conditions, resignation is often the best thing to do. By resigning, you are able to focus on new opportunities without the demands of your current job which in turn can result in getting a better job. If possible, the ideal situation would be to have another job lined upon before leaving. Circumstances will dictate what and when to resign.

\section{Behavior: 31}

Know about Malingerers!

\section{Description:}

Malingerers are individuals looking and acting busy to a fault. They are people who want to look good without working hard.

\section{Application:}

Malingerers make a career out of giving the appearance of being busy but upon scrutiny, results are simply not there. Leaders must know how to spot malingerers. Malingerers should be given the option to change within a reasonable time frame. Be aware, however, unrepentant malingerers create serious morale issues if they are not changed or removed. Firing when you should is a leadership skill. Most are loathed to make this decision but must be used when appropriate. 
Behavior: 32

Make your luck!

\title{
Description:
}

Why do some people have all "the luck?" How and why does that happen? Good leaders do not count on luck as a reliable means of success much less a desirable leader behavior.

\section{Application:}

Leaders often seem to have "good luck" more than others. True enough, however, leadership luck is made of intelligence, thoughtfulness, hard work and according to Thomas Edison, a very "lucky" inventor and businessman, made his luck through mostly perspiration and not just inspiration. Einstein commented on "informed intuition" as a source of success, i.e. a lifetime of study leads one simply to think well than others. Success then is a leadership behavior that is earned and acquired but rarely the result of happenstance or pure luck.

\section{CATEGORY V - BALANCE HOME AND WORK}

\section{Behavior: 33}

Leadership balance!

\section{Description:}

Since Greek and Roman times the concept of a sound mind and a healthy body has been a prescription for a balanced life. Leadership is both mentally and physically demanding and common sense suggests that being physically and mentally fit will enhance a leader's effectiveness. The alternatives of mental fatigue and physical debilitation often lead to illness, stress, and in extreme cases a complete "Burn-Out.

\section{Application:}

Some people are workaholics. Successful leaders find a balance between work and home. For example, they often take that walk, early or late, jog, or hit the gym. The benefits are too numerous to mention. Find what works for you such as meditation, prayer, yoga, physical exercise of any type. The key is trying to do something five or six days a week as many leaders do. President Truman took a vigorous walk every day, President Clinton jogged and President Obama plays basketball. If they can find the time, so can you!

\section{Behavior: 34 \\ Passion at work!}

\section{Description:}

How many times have we heard exhortations to be passionate about what you do? Many executives and HR officers claim that passion is one of the first characteristics they look for in nascent leaders. Passion and enthusiasm is a key leadership behavior -it is what followers expect from their leaders.

\begin{abstract}
Application:
Most modern schools of thought on leadership suggest that many leader behaviors can be taught by attendance at leadership workshops, and mentoring. But passion is a behavior that cannot be taught. You must search deep within your DNA to discover the type of work that drives your passion. You are the only one who can determine what excites you enough to joyfully go to work and perform at one hundred percent. Do your own self assessment and be true to yourself. If you are in the right job, your passion, enthusiasm and exhilarating spirit will shine through which in turn will be recognized by top management.
\end{abstract}

\section{Behavior: 35}

Avoid office romance! 


\section{Description:}

You may not be able to avoid office liaisons (ask Henry Stonecipher former CEO of Boeing) but discretion is the better part of valor (Stonecipher was fired due to an affair with a colleague). We spend an inordinate amount of time, at work; in fact, the largest segment of our life is at work. People naturally develop relationships with colleagues ranging from good friendships to intense, romantic relationships. Messy affairs can easily derail a promising career and destroy ones leadership potential. The Greek sages may had the answer; all things in moderation. Some firms "forbid" office romance and others have standards for personal behaviors at work. History is replete with famous examples of relationships that went beyond the applied norms. Cleopatra and Caesar and Anthony, King Henry VIII, President Clinton and the ongoing saga of the Prime Minister Berlusconi of Italy. These are some famous examples of office affairs that proved detrimental. If you have leadership aspirations you may wish to consider the consequences of office affairs for your career.

\section{Application:}

A suggested rule: Nascent leaders should clearly avoid such entanglements as it may well end badly for all parties.

\section{CATEGORY VI - OTHER CRITICAL CHOICES TO MAKE}

\section{Behavior: 36}

Look like a leader!

\section{Description:}

Leaders are expected to have good grooming and dress well. Curiously, Silicon Valley has spawned a new generation of high tech entrepreneurs who take great pains to dress very casually if not sloppily as a badge of who and what they are. IBM, famous for dress codes, permitted research scientists and programmers to dress casually, providing they were not in contact with clients. Once again, the key is to know what your corporate culture dictates and to dress and act accordingly.

\section{Application:}

- Company dress codes vary greatly now, just be sure you know what yours is.

- It can never hurt to be known as one who overdresses in a tasteful manner.

- It is unprofessional if you dress below the norm

- Looking professional matters more than you think. No one will tell you that your appearance is inappropriate. Why take that chance.

\section{Behavior: 37}

Avoid company politics - when you can!

\section{Description:}

Conflicts between leaders are inevitable when vying for resources and authority. We solve these matters in public service by elections; however, no such handy mechanism exists in the "power" corridors of many companies. Therefore, aspiring leaders must be cautious and wary of entering into frays or openly taking sides in turf wars There could be disastrous negative consequence if you guess wrong or positive outcomes if you guess correctly. Be careful.

\section{Application:}

Sniping, gossiping, ego wars and other similarly boorish behavior will eventually diminish your standing in the eyes of your supervisor. Take the high road and become known as the one who is consistently professional in all respects and at all times. Most leaders do their political jockeying discreetly and privately.

\section{Behavior: 38}

Your resume is a leadership tool! 


\section{Description:}

Always, always have a current resume handy. You simply never know when you will be asked for a resume within your company, your community or by a "head hunter." Sometimes this means responding in minutes with your resume attached to an email. Making excuses and fumbling for time to send a resume will hinder your chances for career advancement.

\section{Application:}

You should keep hard copies handy and know exactly where your resume Efile is. It helps to put the date of the last revision at the end of the resume so you can access the latest version. Also, have a flash drive with just resumes on it for quick access.

\section{Behavior: 39}

Ben Franklin's list for self improvement!

\section{Description:}

Ben Franklin listed behaviors he needed to improve upon. Like Ben Franklin, we know our weaknesses better than anyone. Do a self assessment of what behaviors you need to improve on. For example, spending too much time at work and not enough at home, not exercising, enjoying those alcoholic drinks more than you should. Also, assess your own work performance to determine things you want to excel in. Make a list of priorities and select the one or two most important behaviors to focus upon. Make a plan.

\section{Application:}

Implement your self- improvement plan. For example, take a course on some area you want to improve upon such as computer program enhancement or the ability to read financial statements. Leaders vary greatly in their self improvement behaviors; some actively pursue self improvement (often privately) and others think that they have achieved success and no longer require any change. Dependence upon subordinates may open a gap in what you think you know as opposed to what actually exists. Complacency kills.

\section{Behavior: 40}

Get more education and/or training!

\section{Description:}

Unlike your car's gas tank your brain never seems to stop accepting more knowledge. True, we sometimes feel we are on "overload" yet one of the great joys of life is continuous learning and educational advancement.

\section{Application:}

Attend conferences, workshops, seminars and panels, even if you have to pay your own way. If you return with just one or two ideas you can actually use, it will be worth the time and expense. If you must pay consider the expense, in two ways; first, as a tax deduction and second, as an investment in yourself and your leadership potential. Successful leaders know how to keep learning and so should you.

\section{Behavior: 41}

The dilemma of relocating

\section{Description:}

Wirelessness, teleconferencing, the web, and other technologies have lessened the need for transfers to other locations or parts of the world. Yet, globalization has also created countless opportunities for those who are willing to relocate. Refusal to relocate can derail or significantly slow down a career or it can open new opportunities you never dreamt were possible. IBMers were fond of saying the initials really stood for "I've Been Moved." 
Application:

Many careers have been made and /or significantly enhanced by a willingness to relocate and travel as a major part of one's job. While technology has made communication via phone, email and various kinds of video conferencing, the global dimension of business has actually created more opportunities to work abroad or elsewhere in the United States. Many of the cultures you may be doing business with value personal relationships as a fundamental prerequisite for doing business together. No amount of skyping can do that. So the combination of being willing to relocate and the willingness to use a language facility you may have or be willing to learn is a proven leadership behavior. Ask Carlos Ghosan now CEO of Renault and Nissan and who speaks six languages.

\section{Behavior: 42}

Move out to move up!

\section{Description:}

In the past, in order to move up the corporate ladder you had to move out. It is still somewhat true but changes in business, e.g., mergers, acquisitions, downsizing, technological displacement and the like, may also mean you need to know what to do if you are moved out, excessed, retired early, or simply fired. Being forced to consider new opportunities or simply to find a better job with more of what you want may well involve some tough decision on your part, like quitting and relocating as explained in the previous behavior.

\section{Application:}

Contentment and complacency in one's job may be very hazardous to your career. Therefore, it is an excellent behavior to assume at any given time you could be victimized by budget cutting, reductions in force (RIF) or bankruptcy of your company (Enron, Lehman, Arthur Anderson and many others). Most employees in those firms had no idea of the precariousness of their circumstances. A healthy paranoia about job security should lead you to take every reasonable and prudent measure to weather a sudden career change. Successful leaders create safety nets such as extra savings to survive interim time periods, reducing debts as much as possible, keep in touch with friends and business associates for job openings. Do everything to keep your career moving ahead whether you remain in your current job or decide to move to another organization.

\section{CONCLUSION}

We believe that the insightful behaviors discussed are only effective if the participants take the necessary action to adopt proven leadership behaviors. The behaviors described and the practices recommended in this article, when implemented, can initiate positive change for the nascent leader. The behaviors are practical, applied and adaptable. The authors contend that if these behaviors are performed properly, the nascent leader succeeds. If neglected and performed inadequately, the nascent leader will likely not advance. For the nascent leader to achieve job enrichment and leadership success, one requires practical behavior patterns to be followed in a systematic manner. Failing to embrace these proven behaviors, the nascent leader can remain stymied which in turn creates unfulfilled leadership potential.

We contend that the nascent leader who wishes to achieve leadership success needs some direction. These simple or neglected behaviors can help the nascent leader's advancement. Therefore, the nascent leader needs to have at his/her disposal clear, concise and practical behaviors that could be easily followed. It is the authors' contention that if these practices, as described in this article, are diligently followed then the nascent leader will gain the proficiency needed to accomplish long term success and leadership acumen. In the final analysis the important question for the nascent leader remains, do you have the determination and discipline to learn and apply the behaviors necessary for leadership success?

\section{ACKNOWLEDGEMENT}

The authors express their appreciation to Ms. Kavita Nair for her assistance in the production of this article. 


\section{AUTHOR INFORMATION}

Dennis Payette, Ph.D. is an Associate Professor in the Department of Management, Marketing \& Decision Sciences in the School of Business at Adelphi University. His research interests have focused on pedagogical research related to use of modern teaching methods and technologies. In addition to teaching and research, Dr. Payette's background includes service as a senior administrator at Long Island University and Dowling College.

Anthony Libertella, Ph.D. J.D. is a Professor of Management and Law in the School of Business at Adelphi University. He has served in a number of senior academic positions at various colleges ranging from Executive Vice President/ Provost to Deanships. He was also a practicing attorney specializing in corporate and franchise law. Dr. Libertella's research interests are in strategic management, leadership, and law.

\section{REFERENCES}

1. Benton, D.A. (2000). How to act like a CEO. New York: McGraw-Hill

2. Buckingham, M. (2007). Go put your strengths to work. New York: Free Press.

3. $\quad$ Carnegie, D. (2004). The 5 essential people skills. New York: Fireside.

4. $\quad$ Covey, S.R., Merrill, R.S., Merrill, R.R. (1994). First things first. New York: Free Press.

5. $\quad$ Chopra, D. (2010).The soul of leadership. New York: Harmony Books.

6. Clifton, D.I., Rath, T. (2004). How full is your bucket? Positive strategies for work and life. New York: Gallup Press.

7. Ehrenreich, B. (2005). Bait and switch. New York: Henry Holt and Company.

8. $\quad$ Drucker, P.F. (2004). The daily Drucker. New York: Harper Collins Publishers Inc.

9. Ferrazzi, K. (2009). Who's got your back. The breakthrough program to build beep, trusting relationships that create success- and won't let you fail. New York: Broadway Books.

10. Finzel, H. (2007). The top ten mistakes leaders make. Colorado Springs: David C Cook.

11. Goleman, D. (1995). Emotional intelligence. New York: Bantam Books.

12. Goleman, D. (1998). Working with emotional intelligence. New York: Bantam Books.

13. Harvard Business Review. (1998). What makes a leader. Boston: Harvard Business School Press.

14. Levine, S.R. (2004). The six fundamentals of success. The rules for getting it right for yourself and your organization. New York: Doubleday.

15. Pfeffer, J. (2010). Power. Why some have it - and others don't. New York: Harper Collins Publishers.

16. Rath, T. (2007). Strengths finder 2.0. New York: Gallup Press.

17. Sanborn, M. (2006). You don't need a title to be a leader. New York: Currency Double Day.

18. Scott, S. (2009). Fierce leadership. New York: Crown Business. 